\title{
Vocabulary Building via Language Apps: A Case Study in Hong Kong
}

\author{
Anna Wing-bo TSO \\ The Open University of Hong Kong
}

\begin{abstract}
:
To help students who are learning English as a foreign language (EFL) to gain optimal exposure to authentic English, educators and app designers have developed various digital learning resources, including English vocabulary apps for EFL students, which can, without the barriers of time and space, integrate various media including audio-visual texts, assessment, and/or instant links to online dictionaries and Wikipedia. Nevertheless, English vocabulary learning, as an ongoing process (Schmitt, Schmitt \& Clapham, 2001), means much more than just the convenient access of audio-visual materials. According to $\mathrm{Gu}$ and Johnson (1996), vocabulary learning strategies cover seven main categories of vocabulary learning strategies, which range from learners' beliefs about vocabulary learning, metacognitive regulation, guessing strategies, dictionary strategies, note-taking strategies, memory strategies (rehearsal), memory strategies (encoding), and activation strategies. To what extent vocabulary learning apps are helping students' vocabulary skills is of paramount concern to EFL teachers and apps designers. In light of this, this paper collected data from questionnaires, vocabulary tests, and interviews with EFL students and teachers at university in Hong Kong. It reveals and discusses the effectiveness of current English language learning apps for Hong Kong university students.
\end{abstract}

Keywords: Language apps, vocabulary learning strategies, EFL 